NASA/TM-2004-213295

\title{
Automating the Transition Between Sensorless Motor Control Methods for the NASA Glenn Research Center Flywheel Energy Storage System
}

Elizabeth A. Fehrmann

Ohio Aerospace Institute, Brook Park, Ohio

Barbara H. Kenny

Glenn Research Center, Cleveland, Ohio 
Since its founding, NASA has been dedicated to the advancement of aeronautics and space science. The NASA Scientific and Technical Information (STI) Program Office plays a key part in helping NASA maintain this important role.

The NASA STI Program Office is operated by Langley Research Center, the Lead Center for NASA's scientific and technical information. The NASA STI Program Office provides access to the NASA STI Database, the largest collection of aeronautical and space science STI in the world. The Program Office is also NASA's institutional mechanism for disseminating the results of its research and development activities. These results are published by NASA in the NASA STI Report Series, which includes the following report types:

- $\quad$ TECHNICAL PUBLICATION. Reports of completed research or a major significant phase of research that present the results of NASA programs and include extensive data or theoretical analysis. Includes compilations of significant scientific and technical data and information deemed to be of continuing reference value. NASA's counterpart of peerreviewed formal professional papers but has less stringent limitations on manuscript length and extent of graphic presentations.

- TECHNICAL MEMORANDUM. Scientific and technical findings that are preliminary or of specialized interest, e.g., quick release reports, working papers, and bibliographies that contain minimal annotation. Does not contain extensive analysis.

- CONTRACTOR REPORT. Scientific and technical findings by NASA-sponsored contractors and grantees.
- CONFERENCE PUBLICATION. Collected papers from scientific and technical conferences, symposia, seminars, or other meetings sponsored or cosponsored by NASA.

- SPECIAL PUBLICATION. Scientific, technical, or historical information from NASA programs, projects, and missions, often concerned with subjects having substantial public interest.

- TECHNICAL TRANSLATION. Englishlanguage translations of foreign scientific and technical material pertinent to NASA's mission.

Specialized services that complement the STI Program Office's diverse offerings include creating custom thesauri, building customized databases, organizing and publishing research results ... even providing videos.

For more information about the NASA STI Program Office, see the following:

- Access the NASA STI Program Home Page at http://www.sti.nasa.gov

- E-mail your question via the Internet to help@sti.nasa.gov

- Fax your question to the NASA Access Help Desk at 301-621-0134

- Telephone the NASA Access Help Desk at 301-621-0390

- Write to:

NASA Access Help Desk

NASA Center for AeroSpace Information 7121 Standard Drive

Hanover, MD 21076 
NASA/TM-2004-213295

\section{Automating the Transition Between Sensorless Motor Control Methods for the NASA Glenn Research Center Flywheel Energy Storage System}

Elizabeth A. Fehrmann

Ohio Aerospace Institute, Brook Park, Ohio

Barbara H. Kenny

Glenn Research Center, Cleveland, Ohio

Prepared for the

Second International Energy Conversion Engineering Conference sponsored by the American Institute of Aeronautics and Astronautics Providence, Rhode Island, August 16-19, 2004

National Aeronautics and

Space Administration

Glenn Research Center 
Trade names or manufacturers' names are used in this report for identification only. This usage does not constitute an official endorsement, either expressed or implied, by the National Aeronautics and Space Administration.

Available from

NASA Center for Aerospace Information 7121 Standard Drive

Hanover, MD 21076
National Technical Information Service 5285 Port Royal Road Springfield, VA 22100

Available electronically at http:/ /gltrs.grc.nasa.gov 


\title{
Automating the Transition Between Sensorless Motor Control Methods for the NASA Glenn Research Center Flywheel Energy Storage System
}

\author{
Elizabeth A. Fehrmann \\ Ohio Aerospace Institute \\ Brook Park, Ohio 44142 \\ Barbara H. Kenny \\ National Aeronautics and Space Administration \\ Glenn Research Center \\ Cleveland, Ohio 44135
}

\begin{abstract}
The NASA Glenn Research Center (GRC) has been working to advance the technology necessary for a flywheel energy storage system for the past several years. Flywheels offer high efficiency, durability, and near-complete discharge capabilities not produced by typical chemical batteries. These characteristics show flywheels to be an attractive alternative to the more typical energy storage solutions. Flywheels also offer the possibility of combining what are now two separate systems in space applications into one: energy storage, which is currently provided by batteries, and attitude control, which is currently provided by control moment gyroscopes (CMGs) or reaction wheels. To date, NASA Glenn research effort has produced the control algorithms necessary to demonstrate flywheel operation up to a rated speed of 60,000 RPM and the combined operation of two flywheel machines to simultaneously provide energy storage and single axis attitude control. Two positionsensorless algorithms are used to control the motor/generator, one for low (0 to 1200 RPM) speeds and one for high speeds. The algorithm allows the transition from the low speed method to the high speed method, but the transition from the high to low speed method was not originally included. This leads to a limitation in the existing motor/generator control code that does not allow the flywheels to be commanded to zero speed (and back in the "negative" speed direction) after the initial startup. In a multi-flywheel system providing both energy storage and attitude control to a spacecraft, speed reversal may be necessary.
\end{abstract}

\section{Nomenclature}

$\begin{array}{ll}i & =\text { current } \\ t & =\text { time } \\ v & =\text { voltage } \\ \hat{\omega}_{r} & =\text { estimated rotor position } \\ \hat{\theta}_{r} & =\text { estimated rotor angle } \\ P W M & =\text { pulse width modulation } \\ R P M & =\text { revolutions per minute }\end{array}$

\section{Introduction}

$\mathrm{T}_{\mathrm{H}}^{\mathrm{H}}$

HE advancement of flywheel technology at NASA GRC has been a focus of the Advanced Electrical Systems Branch for the past several years. Most of the efforts have gone into exploring the benefits of flywheels as energy storage for spacecraft because of the advantages flywheel systems offer over the batteries which are used today for much of the energy storage in space. It has been determined that flywheels have the potential for high charge and discharge rates, a high round-trip efficiency, and up to a 15-year long life span in low earth orbit, all of which increase usable power and reduce maintenance costs and overall unit mass. With those characteristics, the flywheel is shown to be a cost- and energy-efficient option for future spacecraft. In addition, flywheels can be used 
to provide attitude control as well as energy storage. Flywheels have advantages over present technology attitude control systems as well by providing larger momentum storage capability and control torques, and both of these features reduce the propellant requirements of the system.

At this point in the flywheel development, however, there is a limitation in the existing Simulink ${ }^{\ddagger}$ control code that does not allow the flywheels to be commanded to zero speed after the initial startup. The control code originally used for the two flywheels at NASA Glenn was sufficient to spin the flywheels up to full speed (60,000 RPM) from zero speed in either the clockwise or the counterclockwise direction. However, once at a speed above 1200 RPM, the low speed sensorless position and speed estimation algorithm was turned off and only the high speed algorithm was used. The original control code contained no means of turning the low speed algorithm back on again if the speed of the wheel decreased below 1200 RPM. In initial testing and in typical operation, this was not a problem because the wheel did not operate below 1200 RPM once started. However, in a multi-flywheel system providing both energy storage and attitude control to a spacecraft, speed and direction reversal and operation through zero speed may be necessary. The new modified code has the ability to switch between angle and speed sensorless estimation methods automatically in order to spin the flywheels through zero. This feature is important for the attitude control portion of the flywheel technology so that the flywheels will have the ability to dictate satellite movement in any angular direction.

\section{Existing Operation}

There are two sensorless rotor angle and speed estimation methods that are used with the flywheel system at NASA Glenn Research Center: signal injection and back electro-motive force (back EMF). Knowledge of the rotor angle is necessary for the algorithm used to control the flywheel motor/generator. A block diagram of this algorithm, known as field orientation control, is shown in Fig. 1 and described in more detail in Ref. 1. A full description of the sensorless methods themselves, and their implementation in the flywheel motor/generator, can be found in Ref. 2. Here, the focus is on the algorithm to transition between the two sensorless methods that is contained within the block labeled "Signal Injection or Back EMF Selection."

At low speeds-for example, between zero and approximately 4000 RPM-the signal injection method can accurately estimate both the position of the rotor and the speed at which the rotor is turning. The angular position is estimated by using an additional voltage, labeled $V_{\text {sig_inj }}$ in Fig. 1, to create a current that contains the angular position information. Therefore, the signal injection method does not rely on the fundamental excitation of the machine to get its estimate. However, the additional current required to operate the signal injection estimation method results in greater losses in the windings (causing additional heat in the motor), which is described further in Ref. 2.

In contrast, the back EMF estimate is based solely on the information contained in the fundamental voltage and current in the motor/generator. However, at low speeds, this information is difficult to correctly determine and the back EMF estimate becomes very inaccurate. It has been determined experimentally that the back

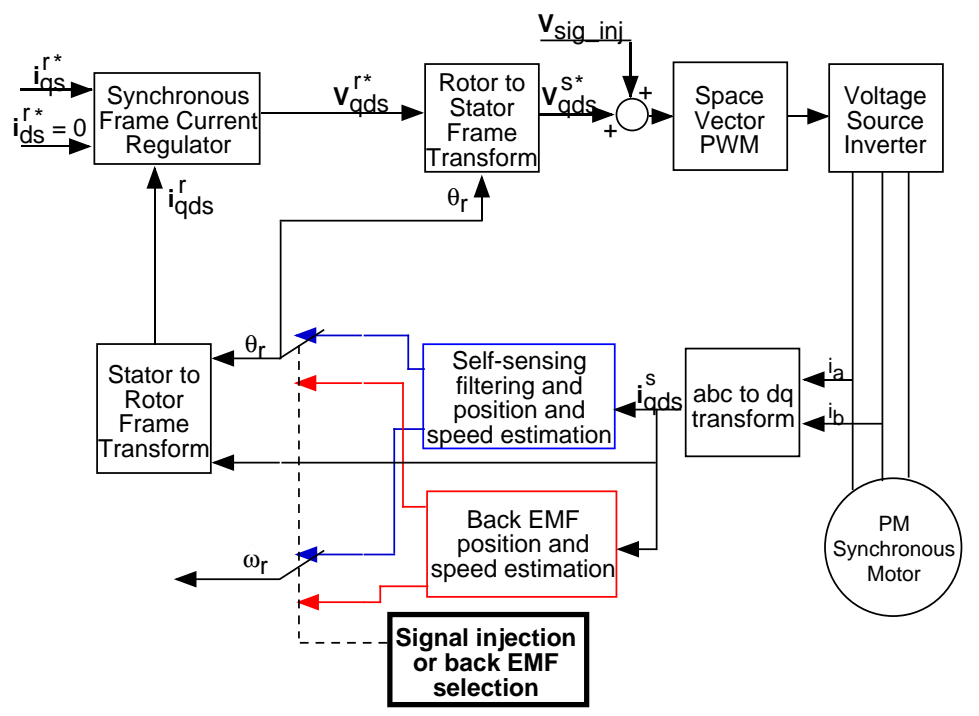

Figure 1. Field Orientation Control Block Diagram for Flywheel Motor/Generator. EMF estimate is reliable at speeds as low as 1200 RPM, therefore, in order to eliminate the extra losses caused by the excess current, the system automatically switches over to the back EMF estimate once the speed is high enough for the back EMF to be a reliable estimate, at which point the voltage supplied to the signal injection is turned off.

There is a speed range between approximately 1000 RPM and 4000 RPM where both the signal injection and the back EMF estimates are correct, and therefore it is within this range that all the transitions between the two sensorless methods occur to increase the probability of a smooth and accurate transition.

\footnotetext{
‡ Trade names or manufacturers' names are used in this report for identification only. This usage does not constitute an official endorsement, either expressed or implied, by the National Aeronautics and Space Administration.
} 
As the speed increases, the back EMF method becomes more and more accurate. However, there are some limitations associated with the original operation since the flywheel could not automatically make the switch from back EMF to signal injection, thereby preventing it from decelerating to zero speed or accelerating in the opposite direction. These problems are described in detail in the next section.

\section{Problem Assessment}

Two events are necessary to successfully transition from the back EMF estimates to the accurate signal injection estimates as the wheel is decelerated through low speeds. First, the signal injection block, which controls the operation of the sensorless method, needs to be turned back on (because it is automatically shut off as the flywheels spin up past 2200 RPM), and given time to find the correct estimates by resetting integrators. The integrators need to be reset every time the flywheel decreases in speed so that the signal injection block has time to attain the correct rotor speed and angular position before the speed drops too low for the back EMF method to lock onto the accurate estimate.

The second event is that the angle estimate needs to be checked for the correct polarity. There is the possibility of the rotor estimate locking onto the wrong pole every time the signal injection method starts. This is because the signal injection technique cannot distinguish between the north and south poles of the rotor magnetic field. The calculations are based on detecting the north pole, so if the algorithm locks onto the south pole instead, the estimated angle would be $180^{\circ}$ off from the actual rotor angle.

\section{Transition Description}

The initial acceleration of the machine from zero speed occurs as follows. The machine is started in the signal injection mode and position and speed are estimated. The motor controller uses the signal injection position and speed estimates from zero speed to 1200 RPM where the transition to the back EMF estimates occurs. At 2200 RPM, the additional voltage necessary for the signal injection method is turned off and the motor continues to accelerate using the back EMF estimates for feedback. Once the signal injection voltage is turned off, the signal injection position and speed estimates become very inaccurate.

For deceleration, the machine begins by using the back EMF estimates for position and speed feedback with the signal injection voltage off. Once the machine decreases to $1900 \mathrm{RPM}$, the signal injection voltage is turned back on. The signal injection position and speed estimates are still inaccurate, however, due to the saturation of the integrators used in the signal injection estimation algorithm. So at 1900 RPM, the integrators are reset to zero and the signal injection position and speed estimates converge on the correct values. At 1000 RPM, the feedback control is changed from using the back EMF estimates to using the signal injection estimates. The machine can now continue to decelerate to zero and then accelerate in the negative, or reverse, direction using the signal injection estimates. Once the machine reaches the negative speed of 1200 RPM, transition to back EMF occurs and at negative 2200 RPM the signal injection voltage is turned off. Thus the machine can accelerate and decelerate through zero to any speed in either direction of rotation and automatically transition between the two estimation techniques as necessary. The rest of this paper will describe the acceleration and deceleration transitions in detail. The Simulink code accomplishing the transitions and the logic behind it will be presented along with the experimental results.

\section{New Control Description}

The new control code in Simulink is comprised of two main blocks. The first block (see Fig. 2) resets the integrators in the "Self-Sensing" block, enables the "Signal Injection" block and checks for whether or not an angle offset of $180^{\circ}$ is needed in the angle estimate in the switch from back EMF to signal injection. The second block (see Fig. 4) enables the startup angle block at the beginning of the code's operation at startup and, if necessary, adds the angle offset determined in the previous block.

The integrator reset was achieved by creating a speed hysteresis with a relay and adding a logical operator on the output of the relay, with the speed value as the input to the relay. The back EMF speed enters the block and passes through an absolute value block to eliminate a potential redundancy in the need for a positive speed code block as well as a negative speed code block. The back EMF speed is then fed through a relay set to transition to "on" mode when the speed is greater than or equal to 2200 RPM, and transition to "off" mode when the speed is less than or equal to 1900 RPM. In the "on" mode, the output of the block equals one, and in the "off" mode, the output of the block is zero. This one or zero signal is inverted using the logical operator "NOT". The inverted signals coming out of the block are sent to the integrators and the enable of the signal injection block, resetting both on the transition from zero to one. At the point where the speed decreases through 1900 RPM, this transition occurs and allows the 
signal injection to pick up the correct angle and speed. The wait block ensures that the signal injection voltage has time to turn on before the code tries to reset the integrators, ensuring correct operation of the low speed estimation code.

The control code also needs a way to determine whether or not it is necessary to add $180^{\circ}$ to the angle to get the correct estimate. The angle offset calculation requires two separate sets of code to correctly get the angular position of the rotor on the spin down. The first section (see Fig. 3) determines whether or not the angle estimate produced by the signal injection block is equal to the angle estimate produced by the back EMF block.

To determine the similarity of the angle estimates, the angle

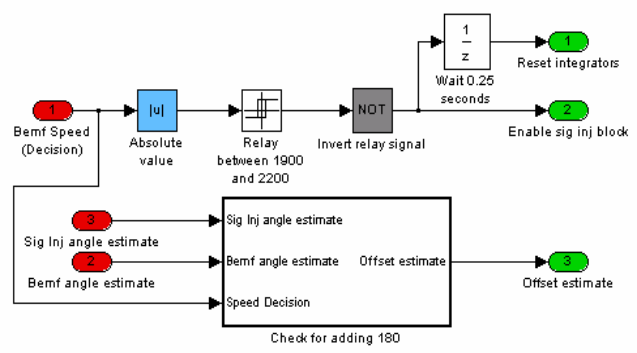

Figure 2. Auto-switch from Back EMF to Signal Injection. from the signal injection block is subtracted from the back EMF angle estimate, and the cosine of the result in radians is compared to zero. If the cosine of the resulting angle difference is negative, the computer can conclude that there is a $90^{\circ}$ to $180^{\circ}$ angle difference between the estimates because the cosine of any radian value between $\pi / 2$ and $3 \pi / 2$ will be less than or equal to zero and therefore be between 90 and 270 in their degree value equivalents. If this scenario is true and the angles are approximately $180^{\circ}$ off, then the angle offset is passed through a D Flip-Flop, a Simulink block that sets the output equal to the input when the reset input "!CLR" is one and the input "CLK" has a "rising edge" (a transition from zero to one).

This offset, if necessary, should be added to the estimated angle only when the signal injection method is used. To guarantee this, the speed from the back EMF estimate is fed through a dead zone, which sets the output to zero between +1800 and -1800 RPM (the range where the signal injection estimate is used) and to the value of the input outside of that zone. This signal is then inverted with a "NOT" operator, making the output one inside the dead zone

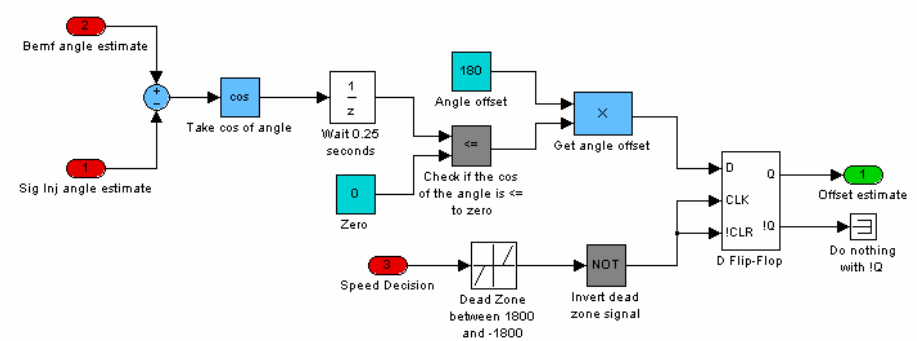

Figure 3. Check for Adding 180 . parameters and zero anywhere else (outside the dead zone parameters). This in turn allows the addition of the angle offset when the speed drops into the +1800 to -1800 RPM bracket. Therefore, during startup and during the transition through zero, this block of code checks to see if the angle offset is needed and passes it to the next block of code.

There is one more condition when it may be necessary to add a $180^{\circ}$ offset to the signal injection angle estimate and that is at start up. The start up routine consists of injecting a DC signal into the motor windings to move the rotor to a known position $^{2}$. Then the signal injection voltage is turned on and the angle is estimated. If the result is correct, no offset is necessary. If the signal injection technique locks onto the rotor's south pole instead of the north pole, the estimate will be different from the known position by $180^{\circ}$ and the offset must be added to the estimate. This means that during start up and as the machine speeds up to 2200 RPM, the signal injection angle offset value will be determined from the start up block. Every other time the machine speed is less than 1800 RPM, the signal injection angle offset value will be determined from the block shown in Fig.3. The code necessary to do this is shown in Fig. 4 and described next.

After determining the need for an angle offset, that information is passed to a second block of code that adds the angle offset of $180^{\circ}$ into the current angle estimate (see Fig. 4). A block is necessary that sets the output equal to the input exactly one time, ignoring any other changes in the state of the input, in order to make sure the startup angle is the one used at the beginning of the run and no other time.

The Simulink S-R Flip-Flop block has these characteristics: if the $\mathrm{R}$ input never changes, than the output remains unchanged, without regards to whether or not the $\mathrm{S}$ input is changing. At the beginning, both inputs are zero, giving a zero on the output of $\mathrm{Q}$, but when $\mathrm{S}$ changes to a one, $\mathrm{Q}$ outputs a one and after that initial change, $\mathrm{S}$ can be either

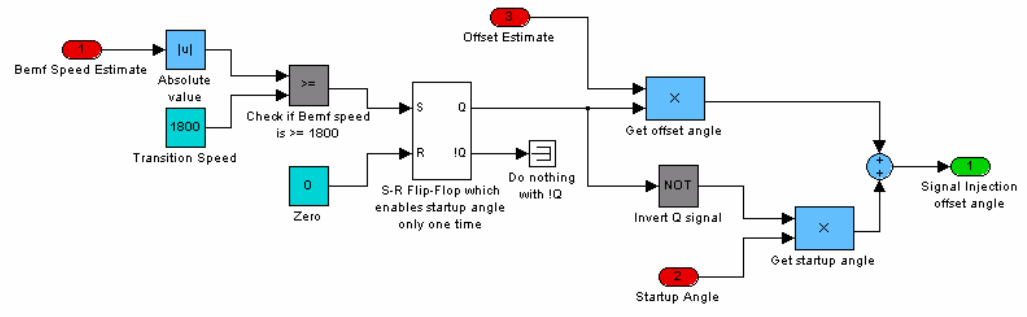

Figure 4. Offset Angle Calculation. 
a one or a zero and the Q output remains at one, unaffected. The back EMF speed estimate enters the block and passes through an absolute value block (again eliminating the need for two separate sections of code dealing with the positive and negative speed directions), and is then compared to the transition speed of 1800 RPM. If the back EMF speed is greater than or equal to 1800 , the "S" input of the S-R block changes from a zero to a one, sending that one through to the "Q" output. This one is then multiplied by the offset estimate determined by the "Check for Adding $180^{\circ}$ ” block described above, and also inverted and multiplied by the startup angle estimate, which results in a zero output, which is then in turn added to the offset estimate. That result is the final angle offset which is ready to be added into the angle estimate to produce the final correct angle. As the absolute value of the flywheels speed first passes 1800, an S-R Flip-Flop block sets the signal injection offset angle to the startup angle, which is calculated accurately in the old section of code. Every other time, the angle offset estimate is received from the "Check for Adding $180^{\circ}$ ” block described above and shown in Fig. 4.

\section{Experimental Results}

The code was tested thoroughly with six different cases. First, the automatic switchover from signal injection to back EMF at 1200 RPM and the signal injection shutoff at 2200 RPM on spin up was tested in both the positive and negative directions. Next, the signal injection enable and integrator reset were tested on spin down at 1900 RPM for both the positive and negative directions. Finally, we tested the ability of the code to spin the wheels through zero by commanding a speed of 100 RPM to -100 RPM and back again.

At the switchover from signal injection to back EMF at 1200 RPM, there is no visible change in any of the observed variables.

After the signal injection has completely shut off, it locks onto a very high positive speed, no matter which direction the wheel was spinning when it was turned off (shown in Fig. 5), therefore the angle thinks that the wheel is spinning at a much faster rate, hence the more rapid up angle repetition seen in Fig. 6.

Figure 7 shows the transition when the signal injection method is restarted. At time $t=0.5$, the integrators are reset and the signal injection estimate locks onto the correct angle in less than two seconds.

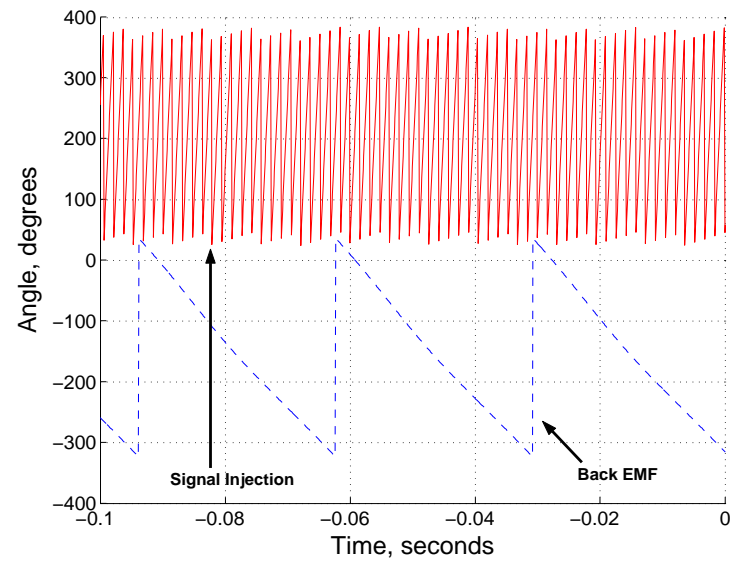

Figure 6. Signal Injection Angle Off.

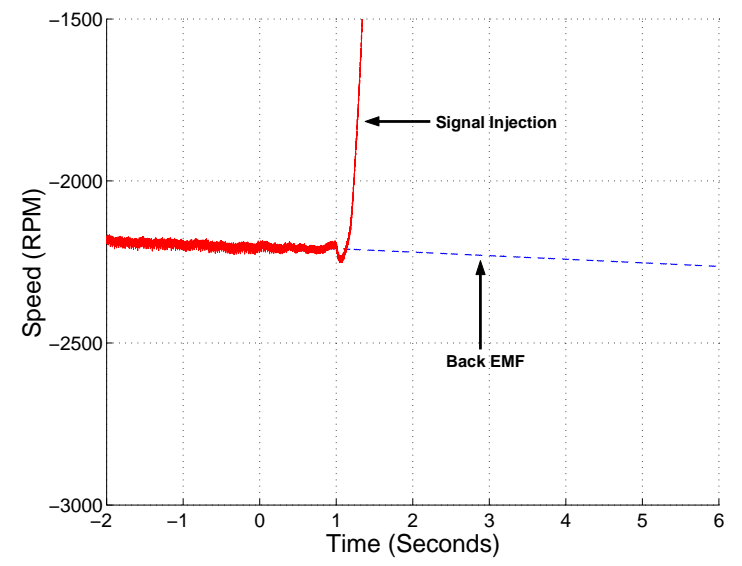

Figure 5. Signal Injection Speed Turning Off.

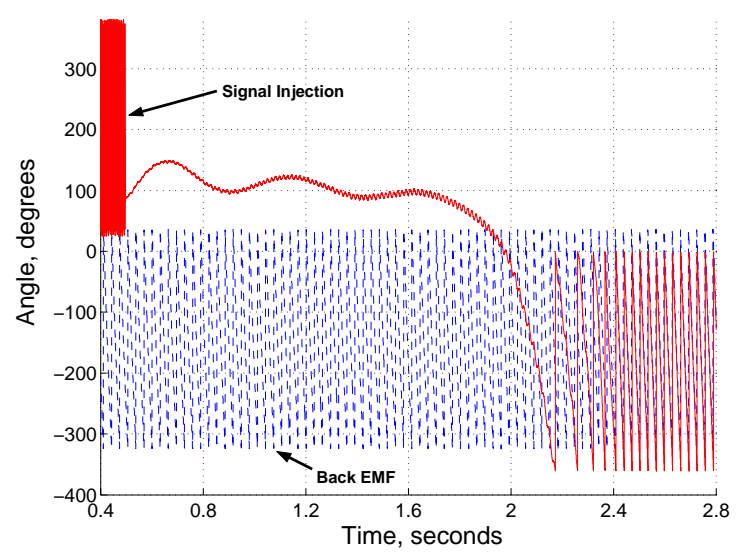

Figure 7. Signal Injection Reset.

Figure 8 shows the close tracking of the back EMF and signal injection estimates after the signal injection portion has locked onto the correct angle. Although the actual rollover points in each saw-tooth waveform are different, the angles are still equivalent because a $360^{\circ}$ angle is the same as a 0 degree one. This means that the 40 degree angle estimate of the back EMF method at 3.04 seconds is the same as the -320 degree one of the signal injection method. So as long as the diagonal sections on the graph are aligned, the angles are the same. The speed estimate also resets, which is shown in Fig. 9. 
One limitation noted in the new algorithm was the rate at which the flywheel could decelerate and successfully transition between the back EMF method and the signal injection method. Due to the time it takes for the integrators in the reset blocks to track the correct estimates, the flywheel could only successfully make the transition from back EMF to signal injection on spin down when decelerating at $15 \mathrm{RPM} /$ second or less. Further experimentation dealing with the timing of the integrator resets, the values to which the integrators reset and the amount of signal injection voltage would be beneficial in allowing the wheels to transition at a higher deceleration rate.

From the angle plots generated by the tests, error plots were also made to show the decreasing error after the integrator reset and also after an angle offset has occurred and been corrected. Figure 10 shows the error between the back EMF angle estimate and the signal injection angle estimate before and after the angle reset. Figure 11 demonstrates the operation of the transition when the signal injection method locks onto the south pole of the rotor field instead of the north pole. The angle offset calculation block detects the approximate $180^{\circ}$ mismatch between the two estimates and then corrects the signal injection estimate by adding the $180^{\circ}$ offset. The offset value bounces between 0 and $180^{\circ}$ from approximately $t=0.5$ to $t=1.5$ because the back EMF speed estimate (which is actually a sine wave of very small amplitude) crosses the 1800 RPM mark more than once, triggering the offset block on and off until the wave completely passes the trigger point. The numerous triggers are not a problem in this case, because the angle estimate is not used for feedback calculations until $1000 \mathrm{RPM}$, when the accurate signal injection angle is dependably computed. The error is never exactly zero as it seems to have an average of $\pm 8^{\circ}$ offset within itself, but this can be corrected in the future with better tuning of each individual estimating technique. At present, there is no way to exactly verify the accuracy of either position estimate because there is no position sensor on the rotor shaft.

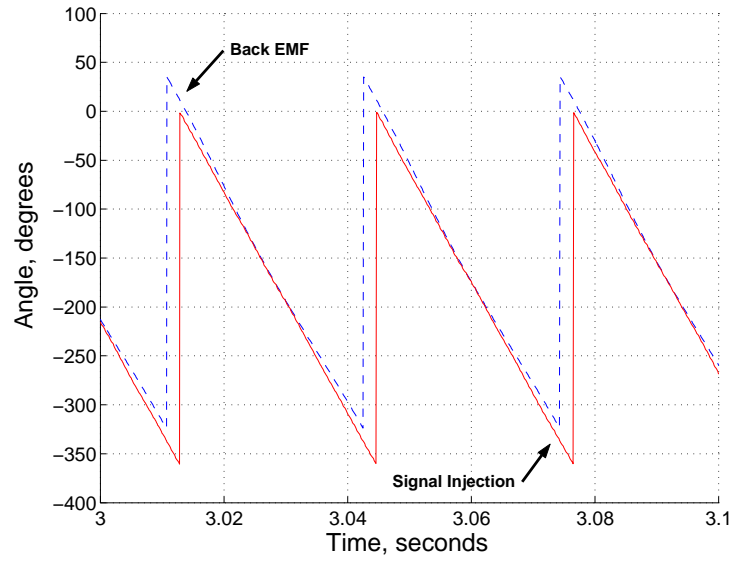

Figure 8. Signal Injection Reset and Tracking the Correct Angle.

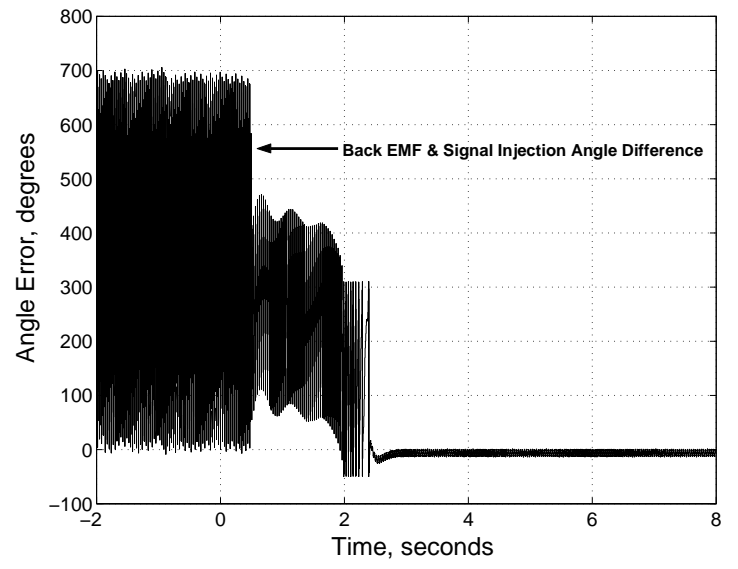

Figure 10. Angle Error between Signal Injection and Back EMF.

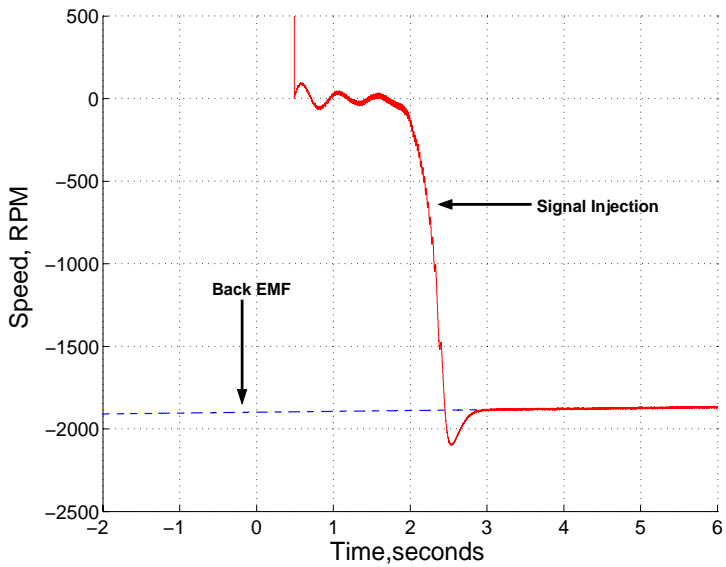

Figure 9. Speed Reset.

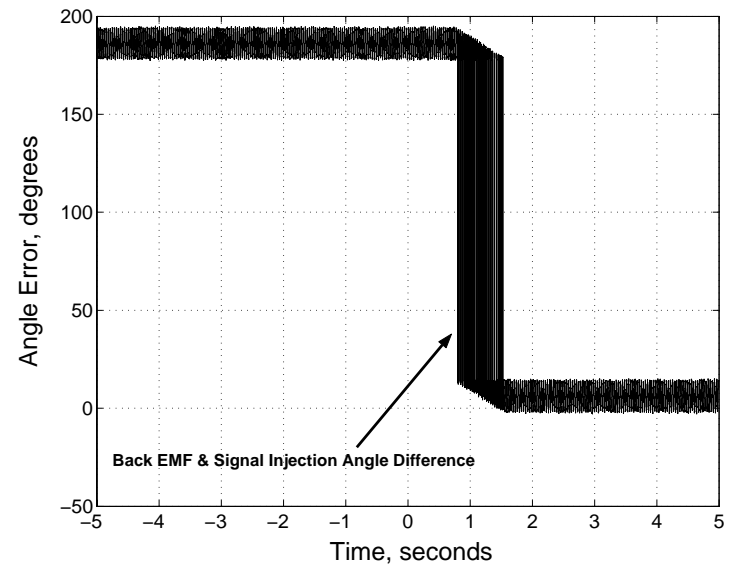

Figure 11. Angle before and after $180^{\circ}$ Offset. 


\section{Conclusion}

This paper has detailed the steps taken to give additional functionality to the NASA GRC flywheels to allow high to low speed transition and speed reversal. New control code was written up in Simulink and tested with the system, showing that the objective-achieving integrator resets and allowing the machine to switch from back EMF to signal injection successfully — was attained. The speeds and angles calculated by both estimation methods and the transitions between the two were shown. The new control code provides a good first solution to the transition problem.

Future work includes duplicating and modifying the new control code to the second flywheel controller for the second flywheel system. Also, flywheel systems comprised of more than two wheels with multiple axes of control will need the capability to move back and forth through zero speed to achieve maximum movement flexibility, and will therefore require a version of this "through zero" code as well. Finally, another area of future work is the acceleration and deceleration rates at which the methods can transition back and forth. Once a particular application is identified and the maximum acceleration and deceleration rates are specified, the new code needs to be tested and may need to be enhanced to ensure it can successfully transition between methods at the highest rates required.

\section{References}

${ }^{1}$ Kenny, Barbara H., Kascak, P., Hofmann, H., Mackin, M., Santiago, W., and Jansen, R., “Advanced Motor Control Test Facility for NASA GRC Flywheel Energy Storage System Technology Development Unit”, NASA/TM-2001-210986, 2001.

${ }^{2}$ Kenny, Barbara H., and Kascak, P., "Sensorless Control of Permanent Magnet Machine for NASA Flywheel Technology Development”, NASA/TM-2002-211726, 2002. 
Public reporting burden for this collection of information is estimated to average 1 hour per response, including the time for reviewing instructions, searching existing data sources, gathering and maintaining the data needed, and completing and reviewing the collection of information. Send comments regarding this burden estimate or any other aspect of this collection of information, including suggestions for reducing this burden, to Washington Headquarters Services, Directorate for Information Operations and Reports, 1215 Jefferson Davis Highway, Suite 1204, Arlington, VA 22202-4302, and to the Office of Management and Budget, Paperwork Reduction Project (0704-0188), Washington, DC 20503.

\begin{tabular}{|l|l|l|}
\hline 1. AGENCY USE ONLY (Leave blank) & $\begin{array}{c}\text { 2. REPORT DATE } \\
\text { September } 2004\end{array}$ & $\begin{array}{r}\text { 3. REPORT TYPE AND DATES COVERED } \\
\text { Technical Memorandum }\end{array}$ \\
\hline
\end{tabular}

\section{TITLE AND SUBTITLE}

5. FUNDING NUMBERS

Automating the Transition Between Sensorless Motor Control Methods for the NASA Glenn Research Center Flywheel Energy Storage System

\section{AUTHOR(S)}

Elizabeth A. Fehrmann and Barbara H. Kenny

WBS-22-319-20-M1

\section{PERFORMING ORGANIZATION NAME(S) AND ADDRESS(ES)}

National Aeronautics and Space Administration

John H. Glenn Research Center at Lewis Field

Cleveland, Ohio 44135-3191

8. PERFORMING ORGANIZATION

REPORT NUMBER

E-14742

\section{SPONSORING/MONITORING AGENCY NAME(S) AND ADDRESS(ES)}

National Aeronautics and Space Administration

Washington, DC 20546-0001

10. SPONSORING/MONITORING AGENCY REPORT NUMBER

NASA TM-2004-213295

AIAA-2004-5602

\section{SUPPLEMENTARY NOTES}

Prepared for the Second International Energy Conversion Engineering Conference sponsored by the American Institute of Aeronautics and Astronautics, Providence, Rhode Island, August 16-19, 2004. Elizabeth A. Fehrmann, Ohio Aerospace Institute, 22800 Cedar Point Road, Brook Park, Ohio 44142; and Barbara H. Kenny, NASA Glenn Research Center. Responsible person, Barbara H. Kenny, organization code 5450, 216-433-6289.

12a. DISTRIBUTION/AVAILABILITY STATEMENT

12b. DISTRIBUTION CODE

Unclassified - Unlimited

Subject Categories: 20 and 44

Distribution: Nonstandard

Available electronically at http://gltrs.grc.nasa.gov

This publication is available from the NASA Center for AeroSpace Information, 301-621-0390.

13. ABSTRACT (Maximum 200 words)

The NASA Glenn Research Center (GRC) has been working to advance the technology necessary for a flywheel energy

storage system for the past several years. Flywheels offer high efficiency, durability, and near-complete discharge capabilities not produced by typical chemical batteries. These characteristics show flywheels to be an attractive alternative to the more typical energy storage solutions. Flywheels also offer the possibility of combining what are now two separate systems in space applications into one: energy storage, which is currently provided by batteries, and attitude control, which is currently provided by control moment gyroscopes (CMGs) or reaction wheels. To date, NASA Glenn research effort has produced the control algorithms necessary to demonstrate flywheel operation up to a rated speed of 60,000 RPM and the combined operation of two flywheel machines to simultaneously provide energy storage and single axis attitude control. Two position-sensorless algorithms are used to control the motor/generator, one for low (0 to $1200 \mathrm{RPM}$ ) speeds and one for high speeds. The algorithm allows the transition from the low speed method to the high speed method but the transition from the high to low speed method was not originally included. This leads to a limitation in the existing motor/generator control code that does not allow the flywheels to be commanded to zero speed (and back in the "negative" speed direction) after the initial startup. In a multi-flywheel system providing both energy storage and attitude control to a spacecraft, speed reversal may be necessary.

14. SUBJECT TERMS

Flywheel energy storage; Sensorless; Speed transition; Motor control; Control code 15. NUMBER OF PAGES 13

\begin{tabular}{|c|c|c|}
\hline $\begin{array}{c}\text { 17. SECURITY CLASSIFICATION } \\
\text { OF REPORT } \\
\text { Unclassified }\end{array}$ & $\begin{array}{c}\text { 18. SECURITY CLASSIFICATION } \\
\text { OF THIS PAGE } \\
\text { Unclassified }\end{array}$ & $\begin{array}{c}\text { 19. SECURITY CLASSIFICATION } \\
\text { OF ABSTRACT } \\
\text { Unclassified }\end{array}$ \\
\hline
\end{tabular}



